\title{
Polymeric piezoelectric actuator substrate for osteoblast mechanical stimulation
}

\author{
C. Frias ${ }^{\mathrm{a}, *, 1}$, J. Reis ${ }^{\mathrm{b}, * *, 1}$, F. Capela e Silva ${ }^{\mathrm{c}}$, J. Potes $^{\mathrm{b}}$, J. Simões ${ }^{\mathrm{d}}$, A.T. Marques $^{\mathrm{a}}$ \\ ${ }^{a}$ Mechanical Engineering Department, Faculty of Engineering of Porto University, Campus FEUP, Rua Roberto Frias s/n, $4200-465$ Porto, Portugal \\ ${ }^{\mathrm{b}}$ Department of Veterinary Medicine, University of Évora, 7002-554 Évora, Portugal \\ c Institute of Agrarian and Environmental Mediterranean Sciences and Department of Biology, University of Évora, 7002-554 Évora, Portugal \\ ${ }^{\mathrm{d}}$ Department of Mechanical Engineering, University of Aveiro, Campus Universitário de Santiago, 3810-193 Aveiro, Portugal
}

\section{A R T I C L E I N F O}

\section{Article history:}

Accepted 17 December 2009

\section{Keywords:}

Polymeric piezoelectric

Actuator

Osteoblast cells

Mechanical stimulation

\begin{abstract}
A B S T R A C T
Bone mass distribution and structure are dependent on mechanical stress and adaptive response at cellular and tissue levels. Mechanical stimulation of bone induces new bone formation in vivo and increases the metabolic activity and gene expression of osteoblasts in culture. A wide variety of devices have been tested for mechanical stimulation of cells and tissues in vitro. The aim of this work was to experimentally validate the possibility to use piezoelectric materials as a mean of mechanical stimulation of bone cells, by converse piezoelectric effect. To estimate the magnitude and the distribution of strain, finite numerical models were applied and the results were complemented with the optical tests (Electronic Speckle Pattern Interferometric Process). In this work, osteoblasts were grown on the surface of a piezoelectric material, both in static and dynamic conditions at low frequencies, and total protein, cell viability and nitric oxide measurement comparisons are presented. (c) 2010 Elsevier Ltd. All rights reserved.
\end{abstract}

\section{Introduction}

Bone is a living structure in constant adaptation and remodeling. The processes of bone resorption and deposition are strongly related to mechanical stimuli (Bourrin et al., 1995; Forwood and Turner, 1995; Hillam and Skerry, 1995; Judex and Zernicke, 2000). Osteocytes and osteoblasts play a central role in mechanical stimuli sensing and transduction in living bone and thus, osteoclastic activity too. Mechanosensation implies that cells respond to an applied force and this mechanism is not necessarily dependent on a chemical stimulus. It has been suggested that forces capable of inducing cell deformation induce changes in membrane channels and on protein structure (Charras et al., 2004; Gudi et al., 1998) and that ultimately, cytoskeleton deformation exerts direct influence on cell nuclei (Bacabac et al., 2006; Burger and Klein-Nulend, 1999; Charras et al., 2004; Jessop et al., 2002). There are several substances produced by osteoblasts that work as messenger molecules, in response to mechanical stimuli, like prostaglandins (particularly PGE2) and nitric oxide (Bakker et al., 2001; Fan et al., 2006; Kanamaru et al., 2001; Smalt et al., 1997). A single osteocyte can disseminate a mechanical stimulus to its surrounding osteocytes via extracellular soluble

\footnotetext{
* Corresponding author. Tel.: +351 225081721; fax: +351225081445

*** Also corresponding author. Tel.: +351 266760840; fax: +351 266760944.

E-mail addresses: clara.frias@fe.up.pt (C. Frias), jmfcr@uevora.pt (J. Reis).

${ }^{1}$ Both authors contributed equally for this work.
}

signaling factors like nitric oxide (Vatsa et al., 2007). A wide variety of devices have been tested for mechanical stimulation of cells and tissues in vitro, namely of osteocytes and osteoblasts (Appleford et al., 2007; Brown, 2000; Lewandowska-Szumiel et al., 2007; McGarry et al., 2008; Tanaka, 1999), although many of these systems are difficult to adapt to an in vivo device. Cell responses depend upon the strain, load and frequency of the stimulus; dynamic, short loading exerts the strongest bone adaptation response, and bone cells tend to accommodate to a routine, so the stimulus must vary in order to elicit a same level of response; a stochastic bone cells response in vitro and in vivo has been reported (Bacabac et al., 2006; Bakker et al., 2001; Burr et al., 2002; Cullen et al., 2001; Hsieh and Turner, 2001; Robling et al., 2001; Tanaka et al., 2003a, 2003b; Turner et al., 1995). Some authors suggest that high frequency associated with a high enough number of cycles are needed to maximize osteoblast proliferation in vitro (Kaspar et al., 2002).

Tanaka reported the use for in vitro assays of a piezoelectric actuator in which the cells were seeded on a collagen gel block. This block was then submitted to uniaxial tension and/or compression by the displacement originated by two piezoelectric ceramic layers by the loading of voltage; both strain and frequency applied may vary (Tanaka, 1999).

The bone has piezoelectric properties, as Fukada and Yasuda (1957) described mechanical stress applied to dried bone produces polarization and submission of bone to an electric field originates strain. The development of biocompatible materials 
that could mimic this behavior could provide a powerful therapeutic tool. The in vitro studies here presented aim to prove the concept of use of piezoelectric materials as a mean to produce controlled and effective mechanical stimulation and to call upon the huge potential of such materials. The values for total protein and viability are similar for cells grown on the devices under the static and dynamic conditions but nitric oxide values are higher under dynamic conditions, suggesting that this increase is due to effective mechanical stimulation and not to cell death or decreased viability.

\section{Methods}

\subsection{Polymeric piezoelectric substrate}

\subsubsection{Physical phenomena of the piezoelectric substrate}

The polymeric piezoelectric films used (polyvinylidene fluoride (PVDF)) were supplied by Measurement Specialties Inc. Company (USA). These $52-\mu$ m-thick films consist of a $12 \times 13 \mathrm{~mm}^{2}$ active area, printed with silver ink electrodes on both surfaces in a $15 \times 40 \mathrm{~mm}^{2}$ die-cut piezoelectric polymer substrate (see Fig. 1a and $\mathrm{b}$ ). It is polarized along the thickness and has as piezoelectric strain constants $d_{z y}=23 \times 10^{-12}$ and $d_{z y}=-33 \times 10^{-12}((\mathrm{~m} / \mathrm{m}) /(\mathrm{V} / \mathrm{m}))$.

Theoretically, based on the converse piezoelectricity effect, when a voltage is applied along the direction of $z$-axis, the polymer strains in the direction of the $y$-axis, given the intrinsic properties of this specific material. The amount of free strain is given by Eq. (1).

$\varepsilon_{y y}=\frac{d_{z y}}{t} V_{a}$

where $t$ is the polymer thickness and $V_{a}$ the applied voltage.

a
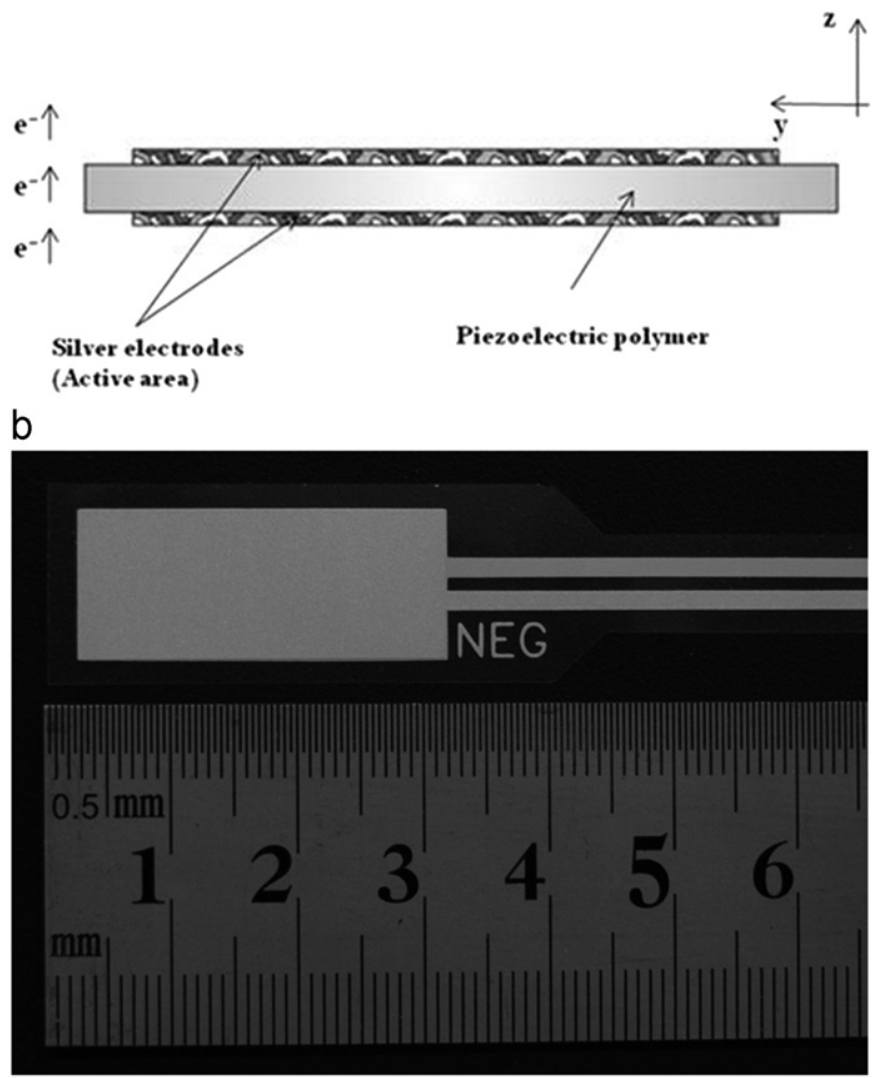

Fig. 1. (a) The image illustrates a piezoelectric polymer. The black region corresponds to the active areas (silver electrode). (b) Picture of the piezoelectric devices used.
2.1.2. Coating the polymeric piezoelectric substrate with PMMA and micro-particles of Bonelike ${ }^{\mathbb{R}}$

To ensure both osteoblasts adhesion to the device surface and electric insulation, the silver electrodes were uniformly covered with an electric insulator material.

The chosen material for covering was an acrylic, poly(methyl methacrylate (PMMA), (PERFEX ${ }^{\mathbb{R}}$, International Dental Products, USA), used alone in the first three layers and a in-forth layer along with $4 \%$ of Bonelike ${ }^{\circledR}(250-500 \mu \mathrm{m})$ particles added (kindly offered by INESCPorto).

The PVDF was covered with homogenous layers of PMMA and Bonelike ${ }^{\mathbb{R}}$ by a Dip-Coating process, at constant velocity of $0.238 \mathrm{~mm} / \mathrm{s}$. Impedance was measured both in saline and culture media, in non-coated and coated devices, under identical conditions as the experimental procedure. The impedance was infinite in the coated devices. The coating was performed in a clean room (INESCPorto)

\subsubsection{Sterilization process of the coated polymeric piezoelectric}

The coated polymeric piezoelectric substrates were submitted to $\gamma$-irradiation (normed dosis of $25 \mathrm{kGy}$ ) for sterilization prior to cell culture (ITN, Lisbon).

\section{2. $\quad$ Numerical modeling (NM)}

NM estimated and quantified the amount of strain distribution along the piezoelectric surface. The mesh was of quadratic piezoelectric solid elements with three degrees of freedom, through Finite Elements Analysis (FEA) using the solver Abaqus 6.7-1 in static conditions. The material properties used for the numerical simulation were provided by the supplier. The model was composed by 9109 nodes.

\subsection{Electronic speckle pattern interferometry process (ESPI)}

To experimentally understand and quantify the real amount of the displacement and its distribution along the piezoelectric actuator surface ESPI was used (LOME-INEGI). The displacement in coated and uncoated devices in the center of the active area was compared along the three axes: $x, y$ and $z$.

\subsection{Cell culture}

The cell line used, MC3T3-E1 cells (11th passage, gently offered by INEB, Porto) exhibit a developmental sequence typical for osteoblasts (Sudo et al., 1983) although various subclones differ in ability to form a bone-like extracellula matrix (ECM) (Wang et al., 1999) and many culture variables influence differentiation and maturation behavior, including the number of passages and the characteristics of the original colony (Chung et al., 1999; Wang et al.,1999; Wenstrup et al., 1996). This cell line has been used in many studies addressing the effects of mechanical stimulation (Jaasma and O'Brien, 2008; Liu et al., 2008; Saunders et al., 2001).

MCT3T3-E1 cells were cultured under standard conditions $\left(37^{\circ} \mathrm{C}, 5 \%\right.$ carbon dioxide), using $\alpha$-MEM medium (Cambrex), $2 \mathrm{mM}$ L-Glutamine (Cambrex), 10\% of bovine fetal serum (Gibco), 0.5\% gentamicin and 1\% amphotericin B (Gibco).

Coated piezoelectric devices (standing on culture dishes, TPP) and controls (standard culture dishes, TPP) were seeded with $16 \times 10^{4}$ cells, with a total volume of $100 \mu \mathrm{l}$ of cell suspension, placed on the active surface of each device (Figs. $2 \mathrm{a}$ and b) and on the center of standard culture dishes. Cells were allowed to adhere to the substrate, before adding the rest of culture medium to all samples, and then grown in both static and dynamic piezoelectric substrates and controls $(n=6)$. On the substrates submitted to dynamic conditions, stimulation was done with an alternating sinusoidal current $(A C)$, of $5 \mathrm{~V}$, at 1 and $3 \mathrm{~Hz}$ for $15 \mathrm{~min}$ at each frequency (24 and $48 \mathrm{~h}$ post-seeding), using NI-6229 multifunction data acquisition (DAQ) and LabView software. All experiments were repeated at least three times.

\subsubsection{Determination of the $\mathrm{pH}$ changes in the cells culture}

The $\mathrm{pH}$ of the cell culture medium was measured in all groups (static and dynamic piezoelectric devices and control standard plates) immediately after stimulation using PHM210 standard pH meter (Meterlab, Radiometer, Copenhagen).

\subsubsection{Determination of viability and metabolic activity with resarzurin method}

The resarzurin-based method utilizes the redox dye resarzurin that upon reduction by metabolically active cells is converted into a highly fluorescent product (resorufin). Nonviable cells have no metabolic capacity and, thus, will not reduce the dye. Therefore, the fluorescence intensity observed in this assay is a measure of the viable cells (Ahmed et al., 1994; Slaughter et al., 1999; Zhi-Jun et al.,1997).

After stimulation, the medium was aspirated and new medium with $10 \%$ resarzurin solution added. Cell cultures were then incubated for $3 \mathrm{~h}$ before 
a

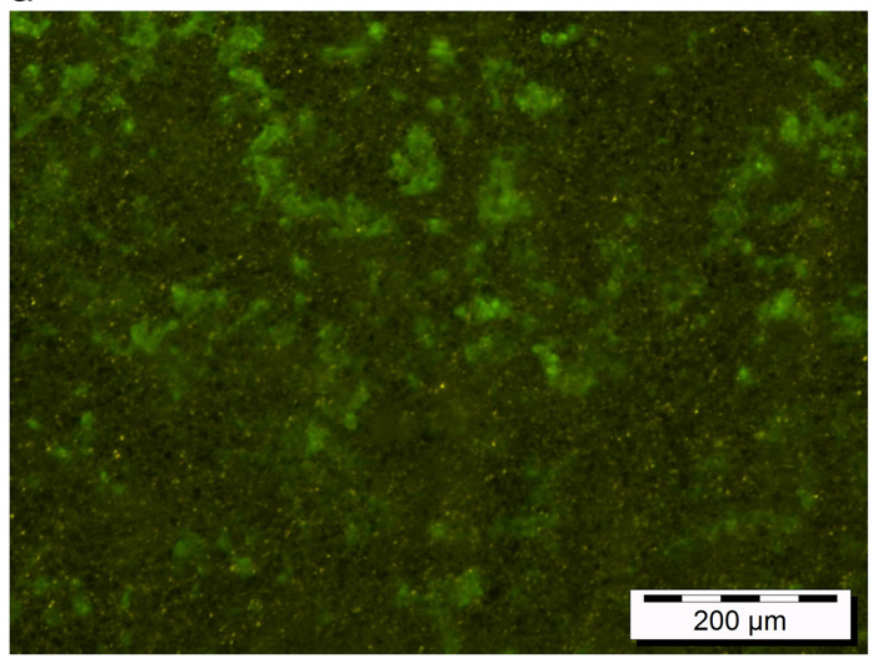

b

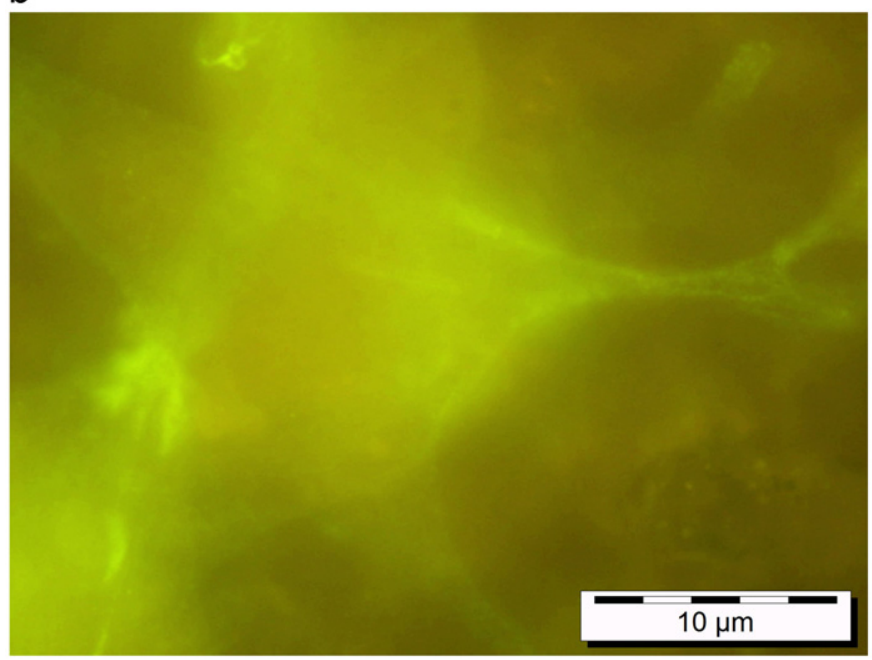

Fig. 2. (a) MC3T3 cells on the active area of the device $2 \mathrm{~h}$ after seeding. Indirect immunofluorescence using primary antibody against actin (Actin, pan Ab-5, Thermo Scientific, used at 1:50) and secondary antibody (Chromeo ${ }^{\mathrm{TM}} 488$ conjugated Goat anti-Mouse IgG, Active Motif 1:500) (microscope Olympus BX41, Olympus Cell A Imaging Software). (b) MC3T3 cells on the active area of the device $2 \mathrm{~h}$ after seeding. Indirect immunofluorescence using primary antibody against actin (Actin, pan Ab-5, Thermo Scientific, used at 1:50) and secondary antibody (Chromeo ${ }^{\mathrm{TM}} 488$ conjugated Goat anti-Mouse IgG, Active Motif 1:500); (microscope Olympus BX41, Olympus Cell A Imaging Software).

collection of samples and fluorescence readings using a fluorescence spectrophotometer (Shimadzu, Japan).

\subsubsection{Measurement of nitric oxide (NO) in culture medium}

NO is a messenger molecule produced in response to mechanical stimulation of osteoblasts and osteocytes, with a large variety of biological functions (Smalt et al., 1997; van't Hof and Ralston, 2001).

NO is quickly oxidized to nitrate and nitrite in biological systems, and these are the two primary, stable and nonvolatile breakdown products of NO. In aqueous buffers and culture conditions nitrite is the principal oxidation product of NO (Ignarro et al., 1993). In this study, culture medium samples were collected immediately after stimulation and NO measured, using NO Assay Kit (Biochain), based on the Griess reaction, after sample deproteinization, and according to the manufacturer's instructions.

\subsubsection{Total protein content}

Cellular protein content was measured with a BCA protein assay kit (Pierce, USA). Briefly, cells were collected from the devices and control standard plates by standard tripsinization procedure, centrifugation of cell suspensions, washed with PBS and centrifuged, twice, and then lysated by adding $200 \mu \mathrm{l}$ of Triton X 100 at $1 \%$ (Sigma) and freeze and thaw cycles (three). $25 \mu \mathrm{l}$ aliquots of cell lysate supernatant were mixed with $200 \mu \mathrm{l}$ volumes of BCA working reagent containing cupric sulfate and bicinchoninic acid (Calbiochem) in microplates and incubated for $30 \mathrm{~min}$ at $37^{\circ} \mathrm{C}$. The resulting optical densities were measured at $570 \mathrm{~nm}$ with a CODA spectrophotometer. Bovine serum albumin was used to generate a standard curve.

\subsubsection{Statistical analysis}

Normal distribution of the results was verified using the Shapiro-Wilk normality test for $n>3$, Levene test for equal variance analysis, and differences between groups tested using one-way ANOVA.

Significant differences were considered at a $P$ value 0.05 . The statistical analysis was done using software OriginPro 7.5 (OriginLab Corporation, USA).

\section{Results}

\subsection{Deposition of thin films in the piezoelectric actuators}

Fig. 3 shows the active area already coated. The coated device has a total thickness of $72 \mu \mathrm{m}$, with the coating thickness of $10-11 \mu \mathrm{m}$ and the electrical isolation of the surface was guaranteed.

\section{a}

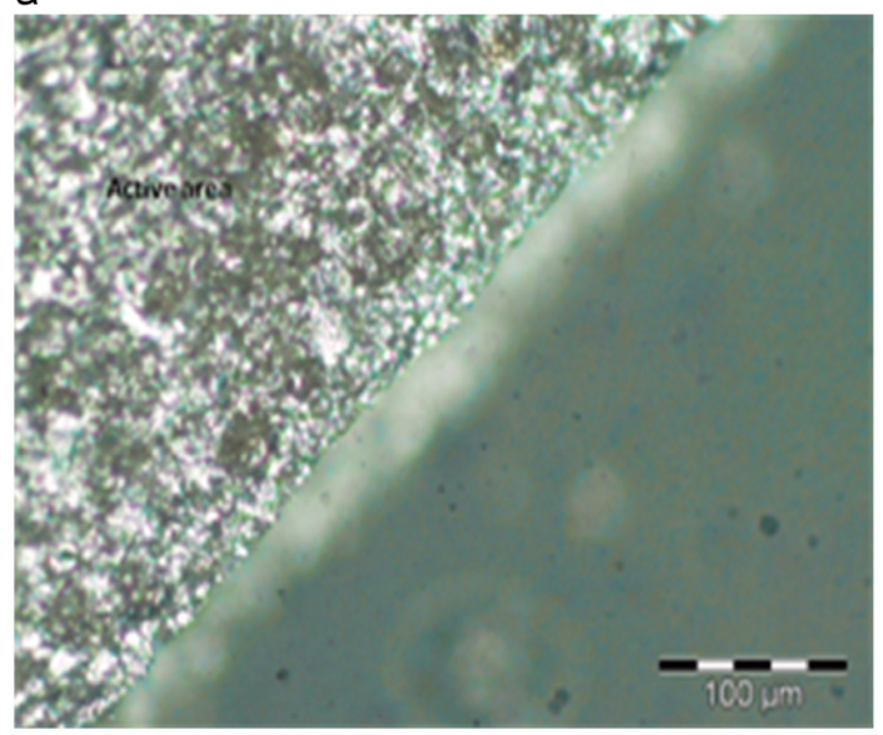

b

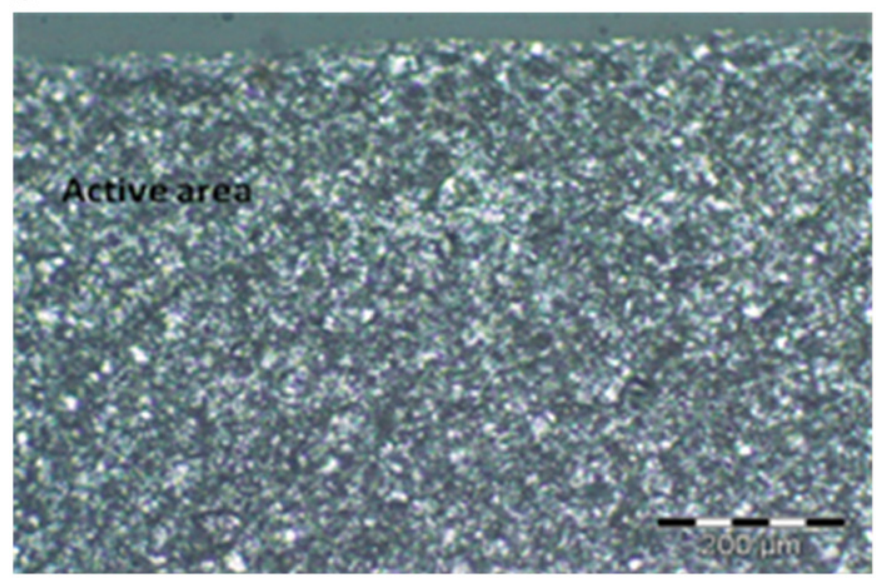

Fig. 3. (a) Optical microscopic (Palatine inverted optical microscope, Olympus PMG3) images of the coatings distribution in the polymeric piezoelectric surface. (b) Optical microscopic (Palatine inverted optical microscope, Olympus PMG3) images of the coatings distribution in the polymeric piezoelectric surface. 


\subsection{Numerical modeling}

NM gave an estimation of strain and displacement distribution along the polymeric piezoelectric surface, at peak voltage. The values are in the range $6.4<y<77.3 \mathrm{~nm}$. The higher displacement was observed in the piezoelectric free extremity. It is possible to observe a sinusoidal numerical perturbation in the encastre region, but the strain values are around $2.2 \mu \varepsilon$ along the piezoelectric surface. These values are near the theoretical ones, see Eq. (1).

\subsection{Electronic speckle pattern interferometry process (ESPI)}

The optical analysis only informs about the actuator active area, the one that is directly exposed to the voltage. The displacement was higher where the cells were seeded, in the central area of the coated devices, in the order of $700 \mathrm{~nm}$ along the $z$-axis, in a semi-sinusoidal fashion. Figs. 4(a) and (b) show ESPI results for uncoated (a) and coated (b) devices subjected to $5 \mathrm{~V}$, and, as it was to be expected, displacement patterns are
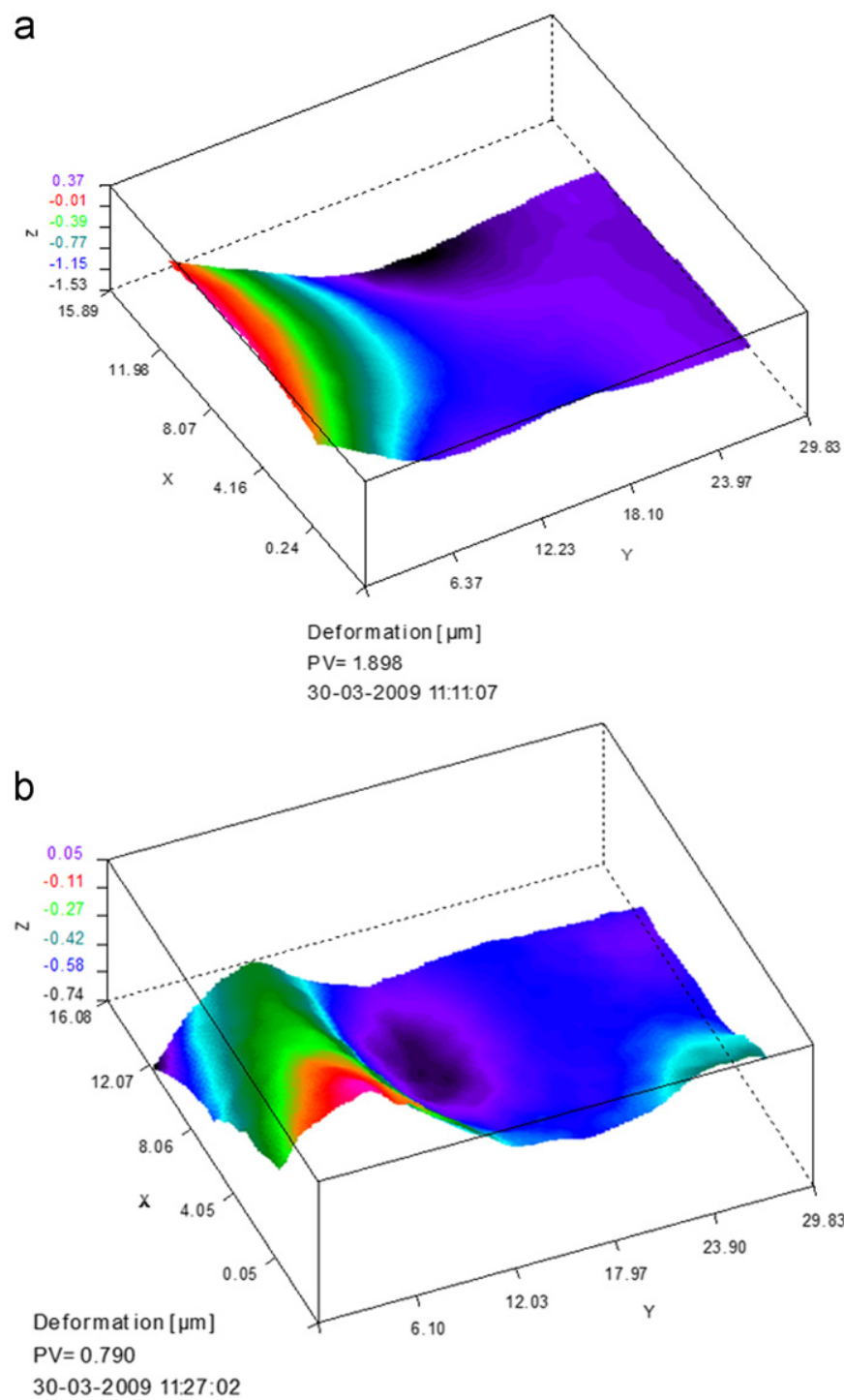

Fig. 4. (a) Displacement variation tridimensionally along uncoated PVDF actuator surface (axis-zz), using EPSI. (b) Displacement variation tridimensionally along coated PVDF actuator surface (axis-zz), using EPSI. distinct due to coating influence on mechanical properties of the device.

\subsection{Cell culture}

\subsection{1. $p H$ measurement}

The culture medium $\mathrm{pH}$ averages after stimulation varied between 7.89 and 7.94 with standard error of the mean $< \pm 0.02$ in all groups, both at 24 and $28 \mathrm{~h}$. No significant differences were found between groups, at either time points.

\subsubsection{Determination of viability and metabolic activity with resarzurin method}

Cell proliferation and viability was affected by both the substrate (actuator vs. customized cell culture dish). Viability was significantly decreased in the groups grown on the device surface (Fig. 5).

Although viability seems to be consistently and slightly higher for the first $48 \mathrm{~h}$ in the group subjected to stimulation, differences were not statistically significant.

\subsubsection{Measurement of nitric oxide in culture medium}

Nitric oxide in culture medium after stimulation was significantly higher in dynamic conditions vs. static, both 24 and $48 \mathrm{~h}$ after seeding (see Fig. 6). When the means of static group at 24 and 48 h were compared, no significant difference was found; the dynamic group at 24 and $48 \mathrm{~h}$ behaved in a similar way, when means of the NO measurements were compared.

\subsubsection{Total protein content}

There were no significant differences in total protein content in control standard dishes, dynamic and static device groups, at time points 24 and $48 \mathrm{~h}$ (Table 1 ).

\section{Discussion and conclusions}

In this work the strain was constant because the applied peak voltage was constant. The frequency varied. According to the definition of piezoelectricity every time a voltage is applied a maximum peak strain is reached and then material recovers the initial shape.

The amount of strain distribution along the piezoelectric material was assumed as an acceptable value for cells to endure. ESPI results on observed displacement along the $z$-axis complement the FNM estimations on the displacement/strain along the $y$-axis.

These results suggest that the devices, both static and dynamic, affected cell viability and proliferation negatively. Although Braga et al. (2007) did not find any evidence of deleterious effects of extracts obtained by immersing PVDF/HA composite membranes in medium used, few studies on PVDF cytocompatibility are available.

Another study using human epithelial cell line L132, refers a proliferation of 37\%, 3 days after seeding, increasing to $45 \%$ at 6 days post-seeding, relating to control, on virgin PVDF (Tabary et al., 2007). Hung et al. (2006) reported PVDF had an inhibitory effect on neural stem cells differentiation and PVDF seemed to decrease consistently MTT reduction activity.

Apart from the impact of the PVDF itself, the coating might improve or diminish protein adsorption and cell adhesion. For adherent cell lines like MC3T3, this is of uttermost importance. Surface properties are also influenced by the sterilization method. In this study, $\gamma$-irradiation (normed dosis $25 \mathrm{kGy}$ ) was used to sterilize the devices prior to cell culture. The method used may 

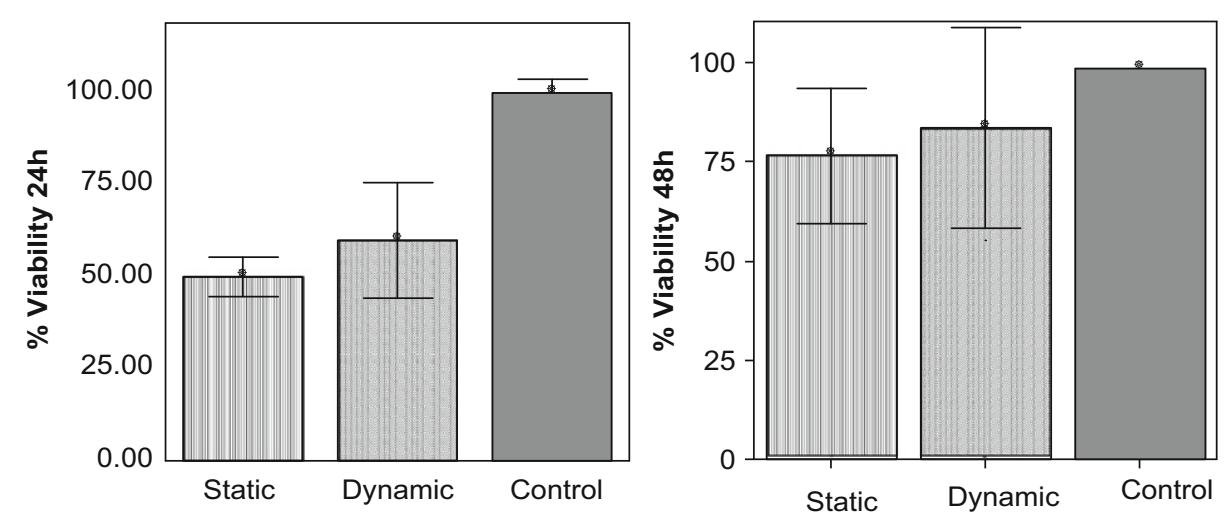

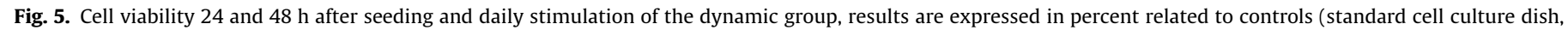
TPP). Bars show means and error bars show means \pm standard error of the mean.
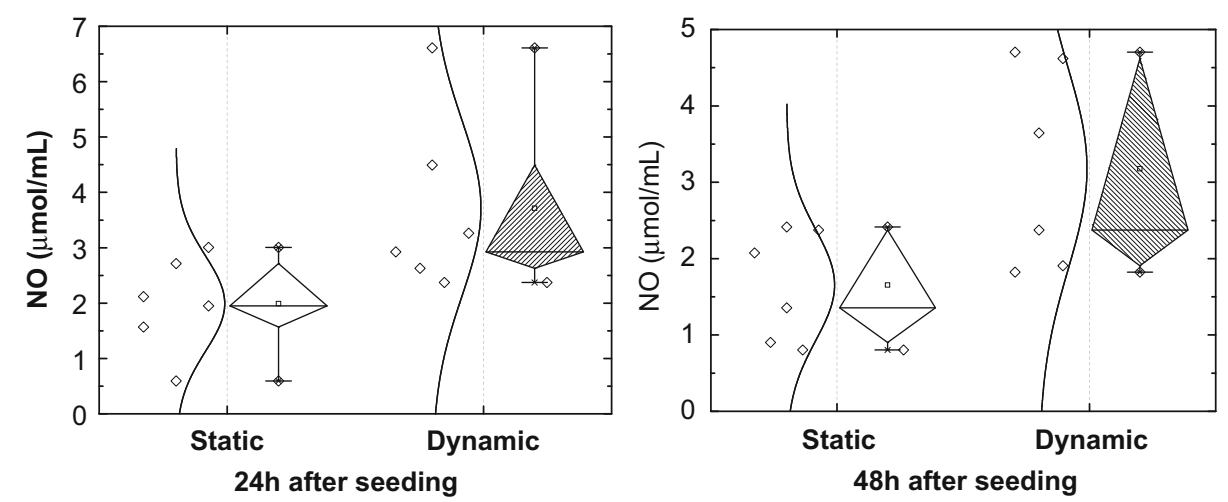

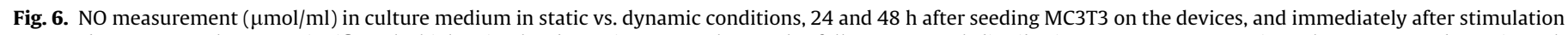

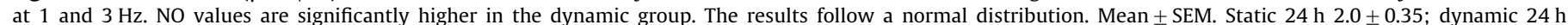
$3.7 \pm 0.65$; static 48 h $1.7 \pm 0.30$; dynamic 48 h $3.2 \pm 0.54$.

Table 1

Total protein content $(\mu \mathrm{g} / \mathrm{ml}) 24$ and $48 \mathrm{~h}$ after seeding in static and dynamic devices and on standard culture dishes (mean \pm SEM for $n=6$ ).

\begin{tabular}{|c|c|c|c|c|c|}
\hline \multicolumn{2}{|l|}{ Static } & \multicolumn{2}{|l|}{ Dynamic } & \multicolumn{2}{|l|}{ Control } \\
\hline $24 \mathrm{~h}$ & $48 \mathrm{~h}$ & $24 \mathrm{~h}$ & $48 \mathrm{~h}$ & $24 \mathrm{~h}$ & $48 \mathrm{~h}$ \\
\hline $6.67 \pm 0.34$ & $16.81 \pm 1.25$ & $6.87 \pm 0.07$ & $16.8 \pm 0.92$ & $7.19 \pm 0.14$ & $20.36 \pm 1.11$ \\
\hline
\end{tabular}

increase protein adsorption on virgin PVDF foils and, although it may not strongly influence cell surface density, as suggested in a study using L929 mouse fibroblasts, it may condition coating oxidation phenomena (Lleixà Calvet et al., 2008). The coating done on the PVDF surfaces in this study allowed electrical insulation and cell adhesion, therefore the viability and proliferation values were higher than those reported in previous studies (Hung et al., 2006; Tabary et al., 2007).

The rise in the NO values in the dynamic devices when compared to the static devices is most likely due to mechanical stimulation, and not to cell death-related phenomena. The total protein content and the resarzurin tests results fail to evidence deleterious effects of the electrical stimulation of the devices, since no significant differences were found between static and dynamic groups. This supports the hypothesis that piezoelectric materials can be effective mechanical stimuli generators.

To our knowledge, cell growth on the surface of a piezoelectric actuator has not been reported before. The advantages of using piezoelectric material for bone cells stimulation are: the control of mechanical ranges stimulation only requires the control of the amount of electrical energy applied; the quicker answer to electric stimulus allows working in physiological frequencies, as are the ones used 1 and $3 \mathrm{~Hz}$, respectively. Another aspect is the possibility, by changing the piezoelectric constants of a biocompatible piezoelectric material, to stimulate bone in different directions apart from the one used in this work.

It would be most interesting to widen the range of frequencies, including higher than the ones used in this study. The amount of displacement can also be varied, within the limitations of the material and its coating.

\section{Conflict of interest statement}

There are no conflicts of interest to declare by the authors.

\section{Acknowledgements}

The authors would like to thank the Portuguese Foundation for Science and Technology (FCT) for financial support under the Grant PTDC/EMEPME/70155/2006 Grants SFRH/BD/22856/2005 and SFRH/BD/31895/2006, to INESCPorto, INEB (OPorto) and ITN (Lisbon), especially to Prof. Doutora Luísa Botelho.

\section{References}

Ahmed, S.A., Gogal Jr, R.M., Walsh, J.E., 1994. A new rapid and simple nonradioactive assay to monitor and determine the proliferation of lymphocytes: an alternative to [3H]thymidine incorporation assay. Journal of Immunological Methods 170, 211-224.

Appleford, M.R., Oh, S., Cole, J.A., Protivínský, J., Ong, J.L., 2007. Ultrasound effect on osteoblast precursor cells in trabecular calcium phosphate scaffolds. Biomaterials $28,4788-4794$. 
Bacabac, R.G., Smit, T.H., Van Loon, J.J.W.A., Doulabi, B.Z., Helder, M., Klein-Nulend, J., 2006. Bone cell responses to high-frequency vibration stress: does the nucleus oscillate within the cytoplasm? The FASEB Journal 20, 858-864.

Bakker, A.D., Soejima, K., Klein-Nulend, J., Burger, E.H., 2001. The production of nitric oxide and prostaglandin E2 by primary bone cells is shear stress dependent. Journal of Biomechanics 34, 671-677.

Bourrin, S., Palle, S., Pupier, R., Vico, L., Alexandre, C., 1995. Effect of physical training on bone adaptation in three zones of the rat tibia. The Journal of Bone and Mineral Research 10, 1745-1752.

Braga, F.J.C., Rogero, S.O., Couto, A.A., Marques, R.F.C., Ribeiro, A.A., Campos, J.S.C., 2007. Characterization of PVDF/HAP composites for medical applications. Materials Research 10, 247-251.

Brown, T.D., 2000. Techniques for mechanical stimulation of cells in vitro: a review. Journal of Biomechanics 33, 3-14.

Burger, E.H., Klein-Nulend, J., 1999. Mechanotransduction in bone-role of the lacuno-canalicular network. The FASEB Journal 13, 101-112.

Burr, D.B., Robling, A.G., Turner, C.H., 2002. Effects of biomechanical stress on bones in animals. Bone 30, 781-786.

Charras, G.T., Williams, B.A., Sims, S.M., Horton, M.A., 2004. Estimating the sensitivity of mechanosensitive ion channels to membrane strain and tension. Biophysical Journal 87, 2870-2884.

Chung, C.Y., Iida-Klein, A., Wyatt, L.E., Rudkin, G.H., Ishida, K., Yamaguchi, D.T., Miller, T.A., 1999. Serial passage of MC3T3-E1 cells alters osteoblastic function and responsiveness to transforming growth factor- $\beta 1$ and bone morphogenetic protein-2. Biochemical and Biophysical Research Communications 265, 246-251.

Cullen, D.M., Smith, R.T., Akhter, M.P., 2001. Bone-loading response varies with strain magnitude and cycle number. Journal of Applied Physiology 91, 1971-1976.

Fan, X., Rahnert, J.A., Murphy, T.C., Nanes, M.S., Greenfield, E.M., Rubin, J., 2006. Response to mechanical strain in an immortalized pre-osteoblast cell is dependent on ERK1/2. Journal of Cellular Physiology 207, 454-460.

Forwood, M.R., Turner, C.H., 1995. Skeletal adaptations to mechanical usage: results from tibial loading studies in rats. Bone 17, S197-S205.

Fukada, E., Yasuda, I., 1957. On the piezoelectric effect of bone. Journal of the Physical Society of Japan 12, 1158-1162.

Gudi, S.R.P., Lee, A.A., Clark, C.B., Frangos, J.A., 1998. Equibiaxial strain and strain rate stimulate early activation of $G$ proteins in cardiac fibroblasts. The American Journal of Physiology-Cell Physiology 274, C1424-C1428.

Hillam, R.A., Skerry, T.M., 1995. Inhibition of bone resorption and stimulation of formation by mechanical loading of the modeling rat ulna in vivo. Journal of Bone Mineral Research 10,683-689.

Hsieh, Y.F., Turner, C.H., 2001. Effects of loading frequency on mechanically induced bone formation. Journal of Bone Mineral Research 16, 918-924.

Hung, C.-H., Lin, Y.-L., Young, T.-H., 2006. The effect of chitosan and PVDF substrates on the behavior of embryonic rat cerebral cortical stem cells. Biomaterials 27, 4461-4469.

Ignarro, L.J., Fukuto, J.M., Griscavage, J.M., Rogers, N.E., Byrns, R.E., 1993. Oxidation of nitric oxide in aqueous solution to nitrite but not nitrate: comparison with enzymatically formed nitric oxide from L-arginine. Proceedings of the National Academy of Sciences of the United States of America 90, 8103-8107.

Jaasma, M.J., O'Brien, F.J., 2008. Mechanical stimulation of osteoblasts using steady and dynamic fluid flow. Tissue Engineering Part A 14, 1213-1223.

Jessop, H.L., Rawlinson, S.C.F., Pitsillides, A.A., Lanyon, L.E., 2002. Mechanical strain and fluid movement both activate extracellular regulated kinase (ERK) in osteoblast-like cells but via different signaling pathways. Bone 31, 186-194.

Judex, S., Zernicke, R.F., 2000. High-impact exercise and growing bone: relation between high strain rates and enhanced bone formation. Journal of Applied Physiology 88, 2183-2191.

Kanamaru, Y., Takada, T., Saura, R., Mizuno, K., 2001. Effect of nitric oxide on mouse clonal osteogenic cell, MC3T3-E1, proliferation in vitro. Kobe Journal of Medical Sciences 47, 1-11.
Kaspar, D., Seidl, W., Neidlinger-Wilke, C., Beck, A., Claes, L., Ignatius, A., 2002 Proliferation of human-derived osteoblast-like cells depends on the cycle number and frequency of uniaxial strain. Journal of Biomechanics 35, 873-880.

Lewandowska-Szumiel, M., Sikorski, K., Szummer, A., Lewandowski, Z., Marczynski, W. 2007. Osteoblast response to the elastic strain of metallic support. Journal of Biomechanics 40, 554-560.

Liu, D., Genetos, D.C., Shao, Y., Geist, D.J., Li, J., Ke, H.Z., Turner, C.H., Duncan, R.L., 2008. Activation of extracellular-signal regulated kinase (ERK1/2) by fluid shear is $\mathrm{Ca}^{2+}$ - and ATP-dependent in MC3T3-E1 osteoblasts. Bone 42, 644-652.

Lleixà Calvet, J., Grafahrend, D., Klee, D., Möller, M., 2008. Sterilization effects on starPEG coated polymer surfaces: characterization and cell viability. Journal of Materials Science: Materials in Medicine 19, 1631-1636.

McGarry, J.G., Maguire, P., Campbell, V.A., O'Connell, B.C., Prendergast, P.J., Jarvis, S.P., 2008. Stimulation of nitric oxide mechanotransduction in single osteoblasts using atomic force microscopy. Journal of Orthopaedic Research 26, 513-521.

Robling, A.G., Burr, D.B., Turner, C.H., 2001. Recovery periods restore mechanosensitivity to dynamically loaded bone. Journal of Experimental Biology 204 3389-3399.

Saunders, M.M., You, J., Trosko, J.E., Yamasaki, H., Li, Z., Donahue, H.J., Jacobs, C.R., 2001. Gap junctions and fluid flow response in MC3T3-E1 cells. The American Journal of Physiology-Cell Physiology 281, C1917-C1925.

Slaughter, M.R., Bugelski, P.J., O'Brien, P.J., 1999. Evaluation of Alamar Blue reduction for the in vitro assay of hepatocyte toxicity. Toxicology in Vitro 13 , 567-569.

Smalt, R., Mitchell, F.T., Howard, R.L., Chambers, T.J., 1997. Induction of NO and prostaglandin E2 in osteoblasts by wall-shear stress but not mechanical strain. The American Journal of Physiology_Endocrinology and Metabolism 273, E751-E758.

Sudo, H., Kodama, H.A., Amagai, Y., Yamamoto, S., Kasai, S., 1983. In vitro differentiation and calcification in a new clonal osteogenic cell line derived from newborn mouse calvaria. Journal of Cell Biology 96, 191-198.

Tabary, N., Lepretre, S., Boschin, F., Blanchemain, N., Neut, C., Delcourt-Debruyne, E., Martel, B., Morcellet, M., Hildebrand, H.F., 2007. Functionalization of PVDF membranes with carbohydrate derivates for the controlled delivery of chlorhexidin. Biomolecular Engineering 24, 472-476.

Tanaka, S.M., 1999. A new mechanical stimulator for cultured bone cells using piezoelectric actuator. Journal of Biomechanics 32, 427-430.

Tanaka, S.M., Alam, I.M., Turner, C.H., 2003a. Stochastic resonance in osteogenic response to mechanical loading. The FASEB Journal 17, 313-314.

Tanaka, S.M., Li, J., Duncan, R.L., Yokota, H., Burr, D.B., Turner, C.H., 2003b. Effects of broad frequency vibration on cultured osteoblasts. Journal of Biomechanics 36, 73-80.

Turner, C.H., Owan, I., Takano, Y, 1995. Mechanotransduction in bone: role of strain rate. The American Journal of Physiology_Endocrinology and Metabolism 269, E438-E442.

van't Hof, R.J., Ralston, S.H., 2001. Nitric oxide and bone. Immunology 103 255-261.

Vatsa, A., Smit, T.H., Klein-Nulend, J., 2007. Extracellular NO signalling from a mechanically stimulated osteocyte. Journal of Biomechanics 40, S89-S95.

Wang, D., Christensen, K., Chawla, K., Xiao, G., Krebsbach, P.H., Franceschi, R.T. 1999. Isolation and characterization of MC3T3-E1 preosteoblast subclones with distinct in vitro and in vivo differentiation/mineralization potential. Journal of Bone and Mineral Research 14, 893-903.

Wenstrup, R.J., Fowlkes, J.L., Witte, D.P., Florer, J.B., 1996. Discordant expression of osteoblast markers in MC3T3-E1 cells that synthesize a high turnover matrix. Journal of Biological Chemistry 271, 10271-10276.

Zhi-Jun, Y., Sriranganathan, N., Vaught, T., Arastu, S.K., Ahmed, S.A., 1997. A dyebased lymphocyte proliferation assay that permits multiple immunological analyses: mRNA, cytogenetic, apoptosis, and immunophenotyping studies. Journal of Immunological Methods 210, 25-39. 